\title{
Simultaneous Quantification of Four Indole Alkaloids in Catharanthus roseus Cell Line C20hi by UPLC-MS
}

\author{
Lihong He, *** Li YANG,* Aizhen XIONG, ${ }^{*}$ Shujuan ZhaO, ${ }^{*}$ Zhengtao WANG, ${ }^{* \dagger}$ and Zhibi HU*† \\ *The Moe Key Laboratory of Standardization of Chinese Medicines and the SATCM Key Laboratory for \\ New Resources and Quality Evaluation of Chinese Medicines, Institute of Chinese Materia Medica, \\ Shanghai University of Traditional Chinese Medicine, Shanghai 201203, P. R. China \\ **Department of Cell Biology, Medical College of Soochow University, Suzhou 215123, P. R. China
}

\begin{abstract}
An ultra-performance liquid chromatography/mass spectrometry method to simultaneously quantify vindoline, catharanthine, serpentine and ajmalicine in Catharanthus roseus cell line C20hi is reported. Samples were extracted with $1 \%$ acetic acid, basified to $\mathrm{pH} 10$ with ammonia, then extracted with ethyl acetate, dried, reconstituted with methanol-1\% acetic acid water solution $(1: 1, \mathrm{v} / \mathrm{v})$ and analyzed using an acetonitrile- $0.1 \%$ formic acid gradient as the mobile phase. Detection was carried out by electrospray ionization mass spectrometry in the positive-ion mode with selective ion monitoring. The analysis of one sample was achieved in $6 \mathrm{~min}$. The limits of detection were $0.46-0.70 \mathrm{ng} / \mathrm{ml} \mathrm{in} \mathrm{cell}$ samples, and $0.10-0.16 \mathrm{ng} / \mathrm{ml}$ in medium samples. The linearity of detection was over the wide range of $1.00-6250.0 \mathrm{ng} / \mathrm{ml}$. Intra- and inter-day accuracies (recovery $88.0-111.8 \%$ ) and precision (RSD $1.25-7.81 \%$ ) showed the performance of the assay. This method provides a more sensitive and high-throughput technique to quantify the four alkaloids in large amount of samples, and will be helpful in high-production cultivar screening.
\end{abstract}

(Received July 14, 2010; Accepted January 24, 2011; Published April 10, 2011)

Periwinkle (Catharanthus roseus (L.) Don), an important medicinal plant, can produce more than 130 alkaloids, including the anti-hypertension ajmalicine, the sedative serpentine, and anti-cancer compounds: vinblastine and vincristine. ${ }^{1}$ Various in vitro cultures of $C$. roseus, such as callus, cell suspensions, hairy roots and multiple shoots, have been developed for the production of indole alkaloids. ${ }^{2}$ A variety of high-performance liquid chromatography (HPLC), GC and MS methods have been developed to identify and quantify alkaloids from in vitro plant cultures. ${ }^{3}$ It has been found that among these alkaloids ajmalicine, serpentine and catharanthine could be detected in most cultures, while the dimeric vinblastine and vincristine could only be detected in multiple shoots, plantlets and intact plants. ${ }^{4,5}$ Since the concentration of vinblastine and vincristine in plants are very limited, efforts to produce them by undifferentiated plant cell cultures have been made for the past 50 years, though no production has yet been demonstrated in cell cultures. ${ }^{6}$

Vincristine and vinblastine are dimeric alkaloids condensed from the monoterpenoids catharanthine and vindoline. Catharanthine can be isolated at high levels from periwinkle cell cultures, but stable production of vindoline has not been observed in these culture systems. ${ }^{7-9}$ It is therefore assumed that the major obstacle of using cell cultures to produce dimeric alkaloids lies in the inability of cell cultures to produce vindoline. ${ }^{9}$ However, vindoline biosynthesis is restored in shoots that regenerated from a non-producing callus, ${ }^{10}$ which indicates that vindoline biosynthesis may be unblocked in cell cultures by fulfilling its regulatory requirements. ${ }^{11}$ There do

$\dagger$ To whom correspondence should be addressed.

E-mail: wangzht@ hotmail.com exist some reports of extremely limited vindoline production in the range of $10-100 \mathrm{ng} / \mathrm{g}$ using sensitive GC-MS, HPLC-MS separation and identification techniques, either from heterotrophic suspension cells (only after 4 passages of culture) or from Agrobacterium transformed cell lines. ${ }^{11,12}$ There are no reports of vindoline production in stable-subcultured, non-transformed cell lines. Therefore, to screen and establish a stable cell line that can biosynthesize both vindoline and catharanthine is the prerequisite to produce vinblastine and vincristine by cell cultures.

During the past 50 years, various analytical techniques have been developed to isolate and quantify alkaloid metabolites in C. roseus plant, tissue and cell cultures. ${ }^{13-16}$ Among them, HPLC coupled with a photo diode array (PDA), fluorescence or UV-detectors are the most widely used. ${ }^{3}$ Most alkaloids in $C$. roseus can be detected by their specific UV absorbance spectra, or the 2D-fluorescence spectra upon good separation as single wavelength. Various extraction protocols and HPLC methods have been developed. ${ }^{3}$ The limits of detection in HPLC analysis are usually in the range of $0.03-1.10 \mu \mathrm{g} / \mathrm{ml}$ and the analysis time requires $20-60 \mathrm{~min} .{ }^{3,14}$ As alkaloids are generally present in low concentrations in cell suspensions, a large amount of biomass and multiple successive extractions are necessary to maximize extraction yield, obtain better separation and distinct peaks. Yet, more than 130 alkaloids in C. roseus plants and more than 60 alkaloids in tissue and cell cultures make extraction and separation both laborious and expensive, and therefore can not meet the increasing requirements of high-throughput analysis for cell-line screening.

Most alkaloids differ in molecular masses and chemical structures, and yield characteristic quasi-molecular ions $[\mathrm{M}+\mathrm{H}]^{+}$ and fragment ions under ESI/MS/MS analysis. They can be 
easily identified from crude extracts by comparing the characteristic ESI/MS/MS spectra and the retention times with authentic standards, even if there are isomers coexist. Zhou et al. demonstrated that catharanthine could be distinguished from its isomers, vindolinine and 19S-vindolinine, according to their different fragment ions under ESI/MS/MS and different retention times under HPLC-ESI/MS. ${ }^{17}$ Therefore, MS detectors provide higher selectivity and sensitivity than UV and fluorescence detectors. The ultra-performance liquid chromatography (UPLC), typical of higher column efficiency and more rapid analysis without loss of resolution compared to traditional HPLC, coupled with mass spectrometry, provides a more sensitive and rapid technique with high selectivity, and can meet the requirement of high-throughput analysis.

C20hi is a fully habituated cell line screened from a 2,4-dichlorophenoxyacetic acid (2,4-D) dependent cell line C20D of C. roseus. It has been stable-cultured in our laboratory for about 10 years. ${ }^{18}$ Its ability to produce ajmalicine and serpentine has been previously reported, ${ }^{18,19}$ but the production of vindoline and catharanthine has not been studied. In this study we simplified the alkaloid extraction method, and developed a UPLC-MS method to quantify the four alkaloids from suspension cultures of C20hi. Here, we evaluated the linearity, recovery, accuracy and precision of this method.

\section{Experimental}

\section{Chemicals and plant materials}

Catharanthine standard was kindly provided by Shanghai R\&D Center for Standardization of Traditional Chinese Medicines. Vindoline, serpentine and ajmalicine standards were purchased from Sigma Corp. (Saint Louis, MO). The purity of all the standards was above 99\%. Methanol and acetonitrile (HPLC grade) were purchased from Sigma Corp. (St. Louis, MO). Acetic acid, ammonia and ethyl acetate were of analytical grade and obtained from Shanghai Chemicals and Reagents Corp. (National Pharmaceutical Corporation, China). Milli-Q water was obtained from purification of double-distilled water using MilliPore (Labconco, USA) $0.22 \mu \mathrm{m}$ membrane filters.

C. roseus fully habituated cell line $\mathrm{C} 20 \mathrm{hi}$ was cultured in B5 basic medium of Gamborg et al. ${ }^{20}$ It was maintained and subcultured as described. ${ }^{18}$ Trichosanthes kirilowii callus, which do not contain the alkaloids of interest, was used as control cells.

\section{UPLC-MS conditions}

The UPLC ${ }^{\mathrm{TM}}$ chromatography system (Waters, Milford, USA) was coupled to a Micromass ZQ mass spectrometer equipped with an electrospray ionization (ESI) source controlled by Masslynx 4.1 software. Sample separations were performed on a Waters Acquity UPLC ${ }^{\circledR}$ BEH C18 column $(50 \mathrm{~mm} \times 2.1 \mathrm{~mm}$, i.d. $1.7 \mu \mathrm{m}$ ) with a flow rate of $0.3 \mathrm{ml} / \mathrm{min}$ at $45^{\circ} \mathrm{C}$. The injection volume was $2 \mu \mathrm{l}$. The mobile phase consisted of acetonitrile (A) and $0.1 \%$ formic acid in water (B). The gradient started from $20 \% \mathrm{~A}$ in $0.5 \mathrm{~min}$, then from $20 \% \mathrm{~A}$ to $35 \% \mathrm{~A}$ in $3 \mathrm{~min}$, and $35 \% \mathrm{~A}$ to $80 \% \mathrm{~A}$ in $1 \mathrm{~min}$, back to $20 \% \mathrm{~A}$ for $1.5 \mathrm{~min}$ equilibration. The analysis lasted for $6 \mathrm{~min}$.

An ESI-MS analysis of indole alkaloids was carried out in the positive-ion mode scanning over the range $\mathrm{m} / z, 100-600$. The quantification method was performed using selected ion monitoring (SIM) with a dwell time of $100 \mathrm{~ms}$. The main parameters were as follows: capillary voltage, $3 \mathrm{kV}$; cone voltage, $35 \mathrm{~V}$; extractor voltage, $3 \mathrm{~V}$; source temperature, $120^{\circ} \mathrm{C}$; desolvation temperature, $350^{\circ} \mathrm{C}$; desolvation gas flow $\left(\mathrm{N}_{2}\right), 550$
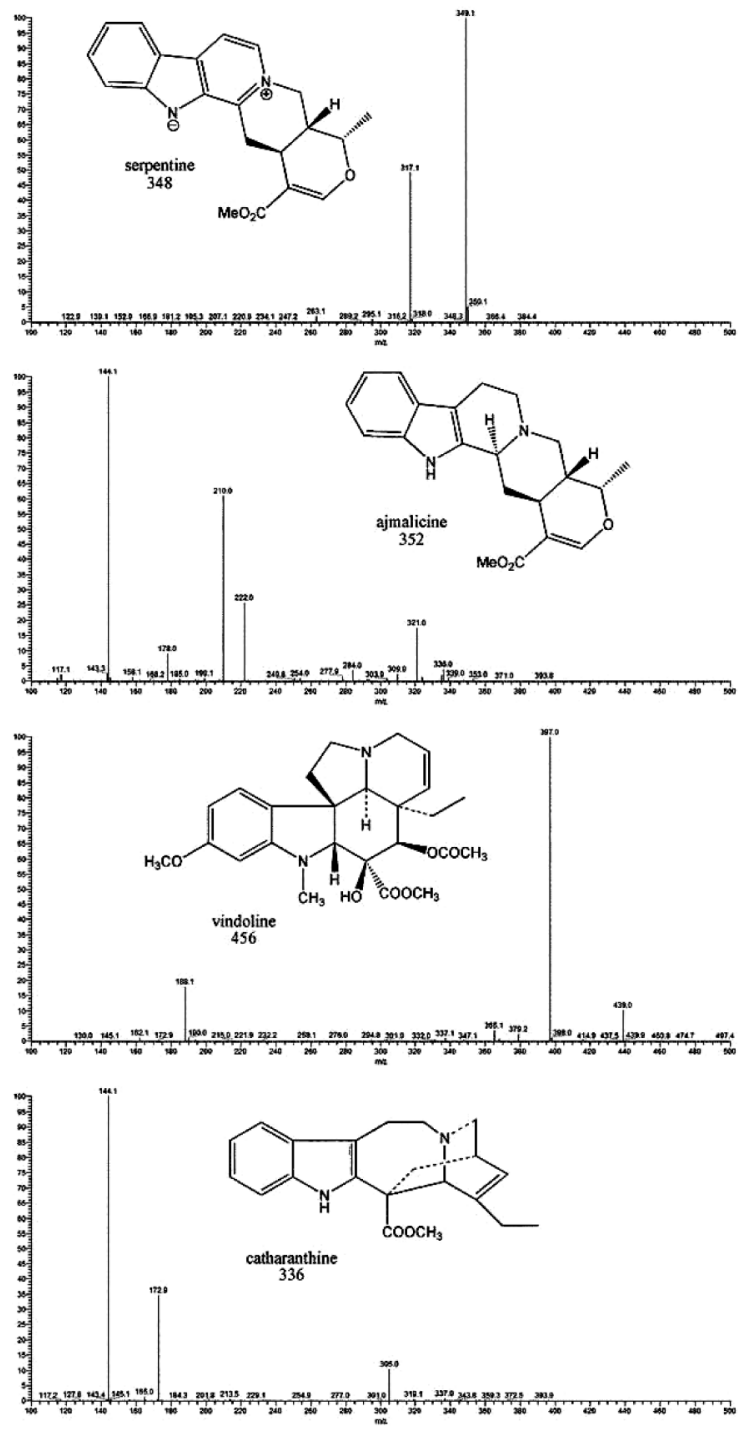

Fig. 1 Chemical structure and typical MS-MS spectra from $[\mathrm{M}+\mathrm{H}]^{+}$ ions of serpentine, ajmalicine, vindoline and catharanthine in alkaloid extract from light induced C20hi cells.

1/h; cone gas flow $\left(\mathrm{N}_{2}\right), 50 \mathrm{l} / \mathrm{h}$. The selective $[\mathrm{M}+\mathrm{H}]^{+}$ions for vindoline, catharanthine, ajmalicine and serpentine were detected at $\mathrm{m} / \mathrm{z}$ 457.2, 337.1, 353.2, 349.2, respectively (Fig. 1).

\section{Sample preparation}

C20hi suspensions cultured for 2 weeks were collected through a nylon cloth filter with $30 \mu \mathrm{m}$ pore size. The cells and culture media were frozen and lyophilized before analysis.

The lyophilized cell samples were ground to a fine powder and stored in a desiccator at room temperature; $0.100 \mathrm{~g}$ of accurately weighed cell powder was transferred to a $10.0-\mathrm{ml}$ tube containing $2.0 \mathrm{ml}$ of $1 \%$ acetic acid in water, incubated in a $37^{\circ} \mathrm{C}$ water bath for $1 \mathrm{~h}$, then ultrasonicated for $75 \mathrm{~min}$. The sample was then centrifuged at $10000 \mathrm{~g}$ for $10 \mathrm{~min}$. The supernatant was carefully transferred to another $10.0 \mathrm{ml}$ tube and the $\mathrm{pH}$ was adjusted to 10.0 by the addition of ammonia. Then, $2.0 \mathrm{ml}$ of ethyl acetate was added and vortexed thoroughly with the supernatant. The mixture was allowed to stand for $20 \mathrm{~min}$ to separate into two layers. The alkaloids were allocated into the upper organic phase. The organic phase was transferred to a 5.0-ml tube. The lower water phase was extracted again 


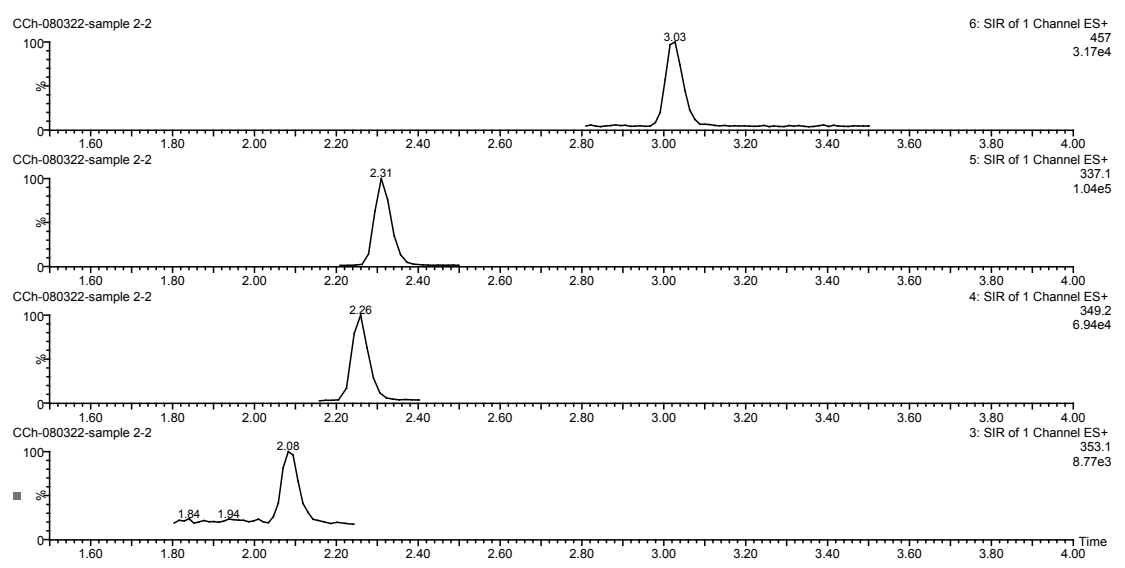

Fig. 2 UPLC-MS chromatograms of indole alkaloids isolated from light induced C20hi cells.

with $2.0 \mathrm{ml}$ of ethyl acetate. The alkaloid extracts were combined and dried under nitrogen gas flow. The residue was redissolved in $0.5 \mathrm{ml}$ of a methanol-1\% acetic acid water solution $(1: 1, \mathrm{v} / \mathrm{v})$ and filtered with a $0.22-\mu \mathrm{m}$ hydrophilic polyethersulfone syringe filter (Anpel, Shanghai, China) prior to UPLC analysis.

The lyophilized culture medium residues were redissolved with $2.0 \mathrm{ml}$ of $1 \%$ acetic acid, adjusted to $\mathrm{pH} 10.0$ with the addition of ammonia, and extracted twice with $2.0 \mathrm{ml}$ of ethyl acetate. The extracts were combined and dried under nitrogen gas flow, redissolved and filtered as described above.

\section{Linearity, limits of detection, and limits of quantitation}

The initial concentration of each alkaloid stock solution was about $0.70 \mathrm{mg} / \mathrm{ml}$. Two mixed stock solutions containing each alkaloid at a concentration of either 6250.0 or $250.0 \mathrm{ng} / \mathrm{ml}$ were subsequently prepared in a methanol-1\% acetic acid water solution $(1: 1, \mathrm{v} / \mathrm{v})$.

A calibration curve for cell samples was prepared using Trichosanthes kirilowii callus, which do not contain the alkaloids of interest. Dried T. kirilowii calli were finely ground in a mortar and filtered through a steel cell strainer $(150 \mu \mathrm{m})$. Calibration standards were prepared using $0.100 \mathrm{~g} \mathrm{~T}$. kirilowii calli powder by diluting stock solutions with a $1 \%$ acetic acid water solution to yield final concentrations of $1.00,2.50,5.00$, $10.0,25.0,50.0,100.0,250.0,1250.0$ and $6250.0 \mathrm{ng} / \mathrm{ml}$. The resulting total volume of calibration working solutions was $2.0 \mathrm{ml}$. An alkaloid extraction procedure was performed as described in the Sample preparation section.

A calibration curve for culture medium samples was prepared using freshly made B5 media. Each aliquot of $100 \mathrm{ml}$ of freshly prepared B5 medium was frozen and lyophilized. Calibration standards were made in the lyophilized medium samples by diluting stock solutions with $1 \%$ acetic acid-water solution to yield final concentrations of 1.00, 2.50, 5.00, 10.0, 25.0, 50.0, $100.0,250.0,1250.0$ and $6250.0 \mathrm{ng} / \mathrm{ml}$. The resulting total volume of calibration working solutions was $2.0 \mathrm{ml}$. An alkaloid extraction procedure was performed as described in the Sample preparation section.

The linearity of each calibration curve was determined by plotting the peak area $(y)$ of each alkaloid standard against the theoretical concentration $(x)$ of each compound added, using a weighted $(1 / x)$ least-square linear regression. The calibration was processed with MassLynx 4.1 QuanLynx Software.

The limit of detection (LOD) and the limit of quantification (LOQ) were determined as the concentration corresponding to a peak area that was three-fold higher and ten-fold higher, respectively, than the baseline noise.

\section{Accuracy and precision of the method}

To test the reproducibility of this method, quality-control (QC) samples were prepared with T. kirilowii calli powder and freshly made B5 media, both of which did not contain the alkaloids of interest. The low, mid and high concentrations of each compound added were 5.00, 10.0 and $20.0 \mathrm{ng} / \mathrm{ml}$ for ajmalicine, $25.0,50.0$ and $100.0 \mathrm{ng} / \mathrm{ml}$ for serpentine, $10.0,20.0$ and $40.0 \mathrm{ng} / \mathrm{ml}$ for vindoline, $50.0,100.0$ and $200.0 \mathrm{ng} / \mathrm{ml}$ for catharanthine, respectively. The highest concentrations were determined according to a pre-quantification of the four alkaloids in C20hi cells, and low concentrations were determined as one half and one quarter of the highest concentrations. The intra-day precision was measured as the relative standard deviation (RSD\%) of the peak area ratio of each alkaloid by the analysis of six consecutive injections of the same sample. The inter-day precision was assayed as the relative standard deviation (RSD\%) of the peak area ratio of each alkaloid by analysis of six QC samples per day, on three consecutive days. The accuracy of this method was evaluated by comparing the calculated mean concentration to the theoretical concentration of each compound added.

\section{Application of the method}

The methodology that we developed was applied to the quantitation of these four indole alkaloids in C20hi suspension cultured cells and media. It has been reported that indole alkaloid accumulation occurred at the beginning of the stationary phase, ${ }^{21}$ and light was important for vindoline biosynthesis in C. roseus seedlings and callus cultures. ${ }^{22,23}$ Therefore, when the C20hi suspension cultures reached the early stationary phase (cultured in darkness for 8 days), they were then transferred and exposed to continuous 6000 Lux light irradiation until the biomass reached a plateau (for an additional 6 days). Cultured cells and media were separated by filtration, and were prepared for alkaloid extraction, as described in the Sample preparation section.

\section{Results and Discussion}

Detection and selectivity of the alkaloids by UPLC-MS

All studied alkaloids from the crude cell extract were first identified by comparisons of the MS/MS spectra and the 

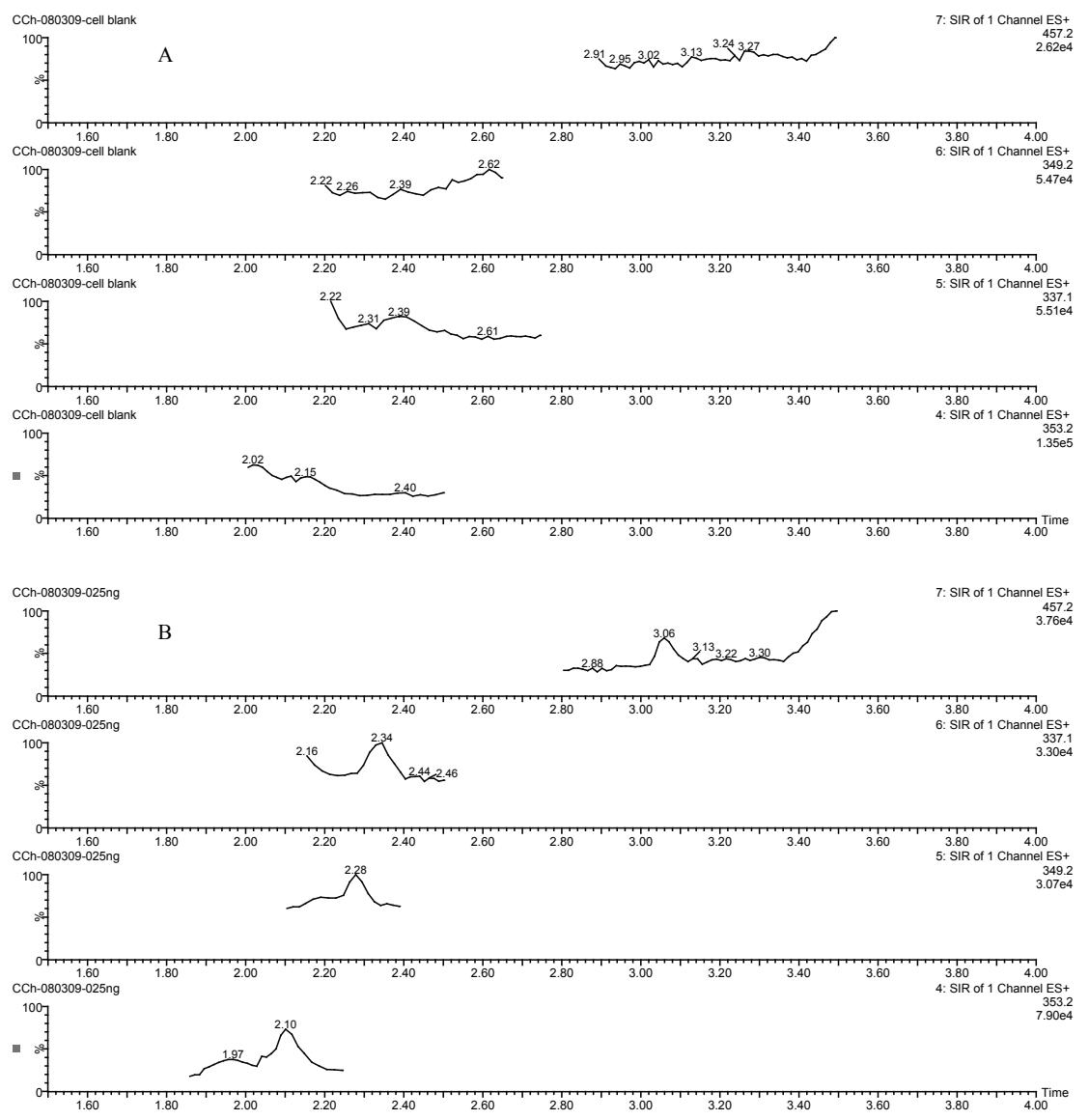

Fig. 3 UPLC-MS chromatograms of indole alkaloids isolated from control cell samples (A) or control cells added with $2.50 \mathrm{ng} / \mathrm{ml}$ combined standards (B).

retention times with those of authentic standards. The MS/MS spectra of alkaloid extract from light induced C20hi cells is shown in Fig. 1. Characteristic fragment ions of the precursor ions at $\mathrm{m} / \mathrm{z} 457,349,337,353$ confirmed the existence of vindoline, serpentine, catharanthine and ajmalicine in C20hi extract in comparison with the standard compounds and references. ${ }^{17,24}$ Further, the fragment ion of 305 at $\mathrm{m} / \mathrm{z} 337$ may indicate the existence of tabersonine, an isomer of catharanthine, and the fragment ion of 321 at $\mathrm{m} / \mathrm{z} 353$ may indicate the existence of an isomer of ajmalicine. ${ }^{24}$ Selected ion monitoring of the cell extract exhibited single peaks in the UPLC-MS chromatograms (Fig. 2), which were identified as vindoline, serpentine, catharanthine and ajmalicine, respectively, by comparisons of the retention times with those standard compounds. Results from Fig. 2 indicated that isomers identified from Fig. 1 had no interference with the quantification of catharanthine and ajmalicine by selected ion monitoring of UPLC-MS.

In order to establish a method to quantify alkaloids in the C20hi cell line and culture medium, a cell line and culture medium that do not contain alkaloids of interest must be chosen. In this study the calli of Trichosanthes kirilowii and the freshly made B5 media were used. T. kirilowii, a well known folk herb of East Asia, has been reported to possess many bioactive components, such as trichosanic acid, trichosanthin, trichosans, diterpene and triterpenoids. ${ }^{25}$ However, no alkaloids, such as ajmalicine, serpentine, vindoline and catharanthine, were reported in T. kirilowii, which was also confirmed in this study. As shown in Fig. 3, in T. kirilowii cells spiked with $2.5 \mathrm{ng} / \mathrm{ml}$ alkaloids mixture, the four alkaloids were well separated at the selected ion, and there were no obvious peaks detected in the control cells at the same retention time as those spiked authentic standards, which indicated that there was no presence of the four alkaloids or their isomers in T. kirilowii calli. Therefore, it was appropriate to use T. kirilowii calli as control cells in the methodology evaluation.

A freshly prepared B5 basic medium was chosen as the control medium for the detection of alkaloids in the medium because, as before, this medium should be completely deficient in the four alkaloids. As shown in Fig. 4, the UPLC-MS chromatograms clearly demonstrated that there were no interference peaks at the selected ion of each alkaloid in the control medium, and in the freshly made B5 media spiked with $2.5 \mathrm{ng} / \mathrm{ml}$ alkaloids mixture, the four alkaloids were well separated at the selected ion. Therefore, it is appropriate for the methodology evaluation.

\section{Linearity}

Linearity in detection was achieved over a wide concentration range from 1.00 to $6250.0 \mathrm{ng} / \mathrm{ml}$ for the four alkaloids detected in both the control cell and the control medium samples. The equations for the regression lines and the regression coefficients are presented in Tables 1 and 2, with all of the LOD and LOQ values. Using weighted $(1 / x)$ least-squares linear regression, the correlation coefficients $(r)$ were $>0.99$ for all four alkaloids both in the control cell and control medium samples. The calculated LOD according to a 3 -fold signal to noise ratio were $0.49,0.52$, 0.70 and $0.46 \mathrm{ng} / \mathrm{ml}$ for ajmalicine, serpentine, vindoline and catharanthine, respectively. 


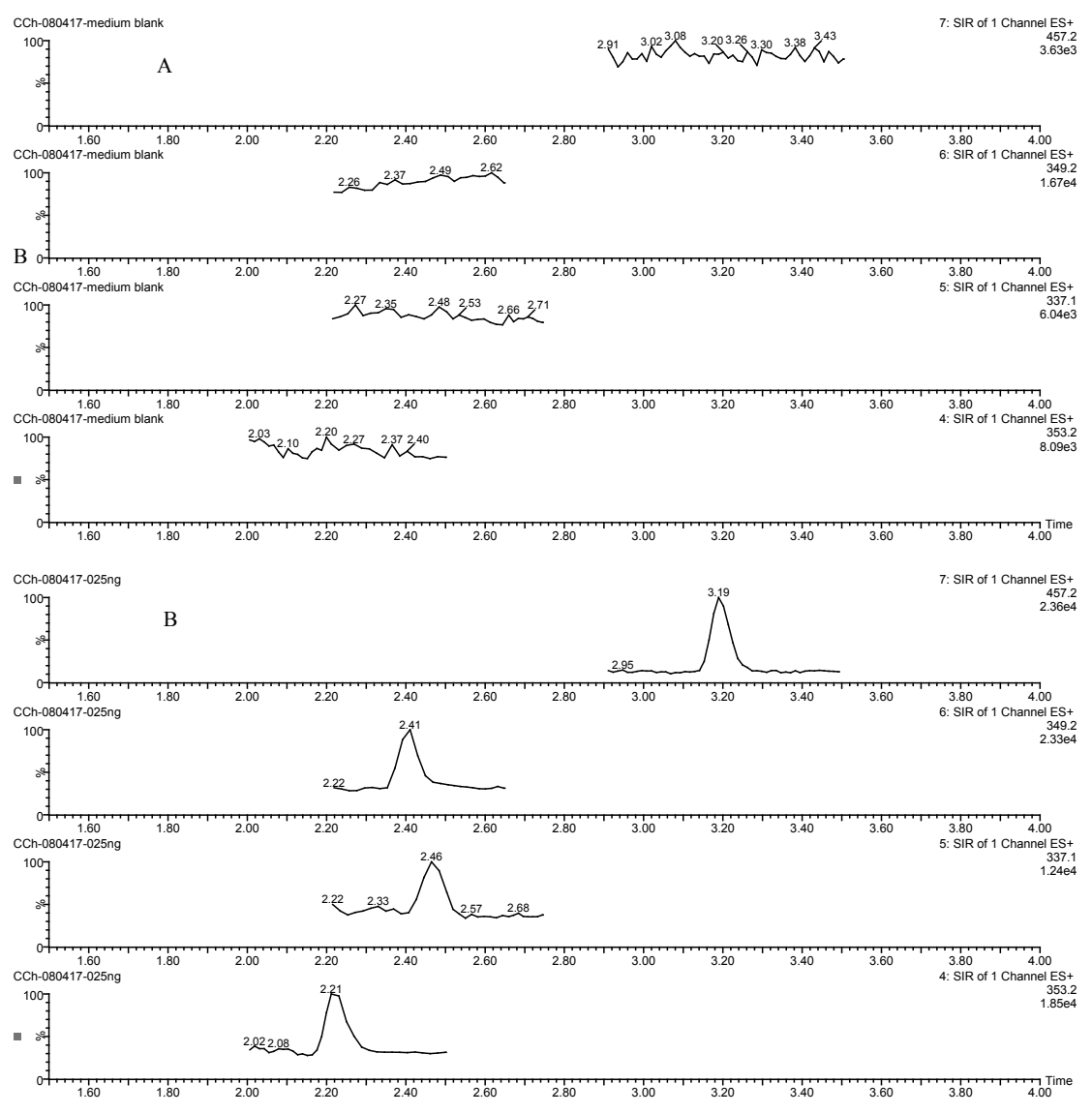

Fig. 4 UPLC-MS chromatograms of indole alkaloids isolated from control B5 medium samples (A) or control medium added with $2.50 \mathrm{ng} / \mathrm{ml}$ combined standards (B).

Table 1 Calibration curves and parameters of indole alkaloid measurements from cell samples

\begin{tabular}{lccccc}
\hline Compound & Linear range/ng ml & Calibration curve & Correlation coefficient $(r)$ & LOQ/ng ml ${ }^{-1}$ & ${\text { LOD} / \mathrm{ng} \mathrm{ml}^{-1}}^{\prime}$ \\
\hline Ajmalicine & $1.00-6250.0$ & $y=215.44 x+825.74$ & 0.9997 & 1.62 & 0.49 \\
Serpentine & $1.00-6250.0$ & $y=239.49 x+191.39$ & 0.9983 & 1.73 & 0.52 \\
Vindoline & $1.00-6250.0$ & $y=315.21 x-361.86$ & 0.9994 & 2.32 & 0.70 \\
Catharanthine & $1.00-6250.0$ & $y=190.19 x-3084.10$ & 0.9985 & 1.52 & 0.46 \\
\hline
\end{tabular}

Table 2 Calibration curves and parameters of indole alkaloid measurements from B5 media samples

\begin{tabular}{lclccc}
\hline Compound & Linear range/ng ml & Calibration curve & Correlation coefficient $(r)$ & LOQ/ng ml & ${\text { LOD} / \mathrm{ng} \mathrm{ml}^{-1}}^{-1}$ \\
\hline Ajmalicine & $1.00-6250.0$ & $y=8.54 x-12.73$ & 0.9994 & 0.37 & 0.11 \\
Serpentine & $1.00-6250.0$ & $y=19.60 x-21.87$ & 0.9985 & 0.44 & 0.13 \\
Vindoline & $1.00-6250.0$ & $y=18.17 x-11.37$ & 0.9982 & 0.33 & 0.10 \\
Catharanthine & $1.00-6250.0$ & $y=1.43 x-0.45$ & 0.9969 & 0.54 & 0.16 \\
\hline
\end{tabular}

\section{Precision and accuracy}

Data for intra- and inter-day precision and accuracy of the method for both cell and medium samples are given in Tables 3 and 4. The intra- and inter-day relative standard deviations (RSDs) were less than 5.25 and $7.81 \%$, indicating acceptable levels of precision and accuracy using the present method. Although the recoveries of ajmalicine at the lowest concentration in medium samples were slightly higher (113.56-114.33\%), the recoveries for vindoline, catharanthine and serpentine were in an acceptable range for UPLC-MS analysis, from 88.00 to $110.27 \%$ at three different concentrations in both the cell and medium samples.
Application to alkaloid measurements in C20hi suspension cultures

The quantification method was successfully applied to the analysis of C20hi cell and medium samples. In a C20hi cell sample which had grown in a suspension culture under continuous light for 6 days, four alkaloids were detected at levels of $80.99,238.95,159.00$ and $8.03 \mathrm{ng} / \mathrm{g}$ dry weights of cells for vindoline, catharanthine, serpentine and ajmalicine, respectively (Table 5). In a sample of purified culture medium in which C20hi cells had been grown, about $27.50 \mathrm{ng} / \mathrm{l}$ medium of serpentine was also detected (Table 5). 
Table 3 Intra-day and inter-day recovery $(\%)$ and precision (RSD\%) of indole alkaloid measurements from cell samples (intra-day, $n=6$; inter-day, $n=6$ series per day, 3 days)

\begin{tabular}{|c|c|c|c|c|c|}
\hline \multirow{2}{*}{ Analyte } & \multirow{2}{*}{$\begin{array}{l}\text { Concentration/ } \\
\mathrm{ng} \mathrm{ml}^{-1}\end{array}$} & \multicolumn{2}{|c|}{ Intra-day } & \multicolumn{2}{|c|}{ Inter-day } \\
\hline & & Recovery & RSD, \% & Recovery & RSD, \% \\
\hline \multirow[t]{3}{*}{ Ajmalicine } & 5.0 & 100.67 & 1.15 & 109.33 & 5.51 \\
\hline & 10.0 & 100.67 & 3.03 & 111.80 & 4.19 \\
\hline & 20.0 & 97.33 & 2.14 & 98.98 & 2.28 \\
\hline \multirow[t]{3}{*}{ Serpentine } & 25.0 & 99.07 & 5.25 & 95.20 & 6.34 \\
\hline & 50.0 & 103.60 & 2.34 & 99.71 & 3.96 \\
\hline & 100.0 & 103.37 & 1.96 & 105.13 & 2.52 \\
\hline \multirow[t]{3}{*}{ Vindoline } & 10.0 & 88.00 & 3.41 & 90.89 & 6.43 \\
\hline & 20.0 & 98.00 & 4.36 & 97.44 & 4.45 \\
\hline & 40.0 & 104.17 & 1.60 & 103.33 & 4.89 \\
\hline \multirow[t]{3}{*}{ Catharanthine } & 50.0 & 106.13 & 3.48 & 110.27 & 3.95 \\
\hline & 100.0 & 105.62 & 3.80 & 109.55 & 4.56 \\
\hline & 200.0 & 102.00 & 1.79 & 104.79 & 2.78 \\
\hline
\end{tabular}

Table 4 Intra-day and inter-day recovery (\%) and precision (RSD\%) of indole alkaloid measurements from B5 media samples (intra-day, $n=6$; inter-day, $n=6$ series per day, 3 days)

\begin{tabular}{ccccccc}
\hline \multirow{2}{*}{ Analyte } & $\begin{array}{c}\text { Concentration/ } \\
\text { ng ml }^{-1}\end{array}$ & \multicolumn{2}{c}{ Intra-day } & & \multicolumn{2}{c}{ Inter-day } \\
\cline { 3 - 4 } \cline { 6 - 7 } Ajmalicine & 5.0 & 113.56 & 1.25 & & 114.33 & 1.72 \\
& 10.0 & 96.83 & 2.30 & & 100.28 & 3.32 \\
& 20.0 & 98.00 & 3.03 & & 100.50 & 5.22 \\
Serpentine & 25.0 & 88.27 & 2.82 & & 94.07 & 4.42 \\
& 50.0 & 88.10 & 2.47 & & 92.71 & 4.57 \\
Vindoline & 100.0 & 104.05 & 1.81 & & 98.50 & 5.05 \\
& 10.0 & 98.00 & 2.67 & & 95.11 & 4.67 \\
& 20.0 & 95.67 & 1.95 & & 91.97 & 4.92 \\
Catharanthine & 40.0 & 94.96 & 2.29 & & 93.90 & 2.30 \\
& 50.0 & 106.00 & 4.22 & & 105.10 & 5.22 \\
& 100.0 & 90.32 & 4.10 & & 91.06 & 6.50 \\
& 200.0 & 104.09 & 5.06 & & 110.01 & 7.81 \\
\hline
\end{tabular}

Table 5 Concentrations of indole alkaloids isolated from light-induced C20hi cells and the culture medium (as a content of $\mathrm{ng} / \mathrm{g}$ dry weight of cells, or $\mathrm{ng} / \mathrm{l}$ culture medium)

\begin{tabular}{lcccc}
\hline Analyte & Vindoline & Serpentine & Ajmalicine & Catharanthine \\
\hline Cell & 80.99 & 159.00 & 8.03 & 238.95 \\
Medium & - & 27.50 & - & - \\
\hline
\end{tabular}

\section{Conclusion}

The UPLC-MS method described here provides higher sensitivity and a shorter analysis time for the simultaneous quantitation of the four alkaloids; the limits of quantification were $1.52-2.32 \mathrm{ng} / \mathrm{ml}$, about 1000-times lower than that reported for the HPLC method. ${ }^{14}$ The total analysis time is $6.0 \mathrm{~min}$, including the column washing and equilibration time, a significant reduction in the analysis time than that of the common HPLC method. ${ }^{3}$ Therefore, the UPLC-MS method we describe here enables the detection of extremely dilute alkaloids and high sample throughput, and will enhance future studies of indole alkaloids biosynthesis in C. roseus.

\section{Acknowledgements}

Financial support of the National Science and Technology Major Projects of China (2009ZX09502-013, 2009ZX09502-021 and 2009ZX09502-024) is gratefully acknowledged.

\section{References}

1. R. Van Der Heijden, D. I. Jacobs, W. Snoeijer, D. Hallared, and R. Verpoorte, Curr. Med. Chem., 2004, 11, 607.

2. A. Pietrosiuk, M. Furmanowa, and B. Łata, Phytochem. Rev., 2007, 6, 459.

3. S. Hisiger and M. Jolicoeur, Phytochem. Rev., 2007, 6, 207.

4. K. Hirata, M. Horiuchi, T. Ando, K. Miyamoto, and Y. Miura, J. Ferment. Bioeng., 1990, 70, 193.

5. J. Zhao and R. Verpoorte, Phytochem. Rev., 2007, 6, 435.

6. S. Mahroug, V. Burlat, and B. St-Pierre, Phytochem. Rev., 2007, 6, 363.

7. R. T. Tyler, W. G. W. Kurz, and B. D. Panchuk, Plant Cell Rep., 1986, 3, 195.

8. V. De Luca, J. Balsevich, R. T. Tyler, and W. G. W. Kurz, Plant Cell Rep., 1987, 6, 458.

9. F. Vázquez-Flota, V. De Luca, M. Carrillo-Pech, A. Canto-Flick, and M. D. Miranda-Ham, Mol. Biotechnol., 2002, 22, 1.

10. F. Constabel, P. Gaudet-LaPrairie, W. G. W. Kurz, and J. P. Kutney, Plant Cell Rep., 1982, 1, 139.

11. T. Naaranlahti, S. P. Lapinjoki, A. Huhtikangas, L. Toivonen, U. Kurtén, V. Kauppinen, and M. Lounasmaa, Planta Med., 1989, 55, 155.

12. B. R. O'Keefe, G. B. Mahady, J. J. Gills, C. W. W. Beecher, and A. B. Schilling, J. Nat. Prod., 1997, 60, 261.

13. R. Bhadra, S. Vani, and J. V. Shanks, Biotechnol. Bioeng., 1993, 41,581 .

14. C. Tikhomiroff and M. Jolicoeur, J. Chromatogr., A, 2002, 955, 87.

15. Y. H. Choi, K. P. Yoo, and J. Kim, Chem. Pharm. Bull., 2002, 50, 1294.

16. L. Barthe, J. P. Ribet, M. Pélissou, M. J. Degude, J. Fahy, and A. Duflos, J. Chromatogr., A, 2002, 968, 241.

17. H. Zhou, Y. P. Tai, C. Sun, and Y. J. Pan, Phytochem. Anal., 2005, 16, 328.

18. Z. G. Zheng, Y. Zhou, D. Liu, and Z. B. Hu, Acta Bot. Sin., 2002, 44, 1146.

19. Z. G. Zheng and M. Wu, Plant Sci., 2004, 166, 507.

20. O. L. Gamborg, R. A. Miller, and K. Ojima, Exp. Cell Res., 1968, 50, 151.

21. P. Gantet, N. Imbault, M. Thiersault, and P. Doireau, Plant Cell Physiol., 1998, 39, 220.

22. F. A. Vázquez-Flota, B. St-Pierre, and V. De Luca, Phytochemistry, 2000, 55, 531.

23. J. Zhao, W. H. Zhu, and Q. Hu, Plant Growth Regul., 2001, $33,43$.

24. F. Ferreres, D. M. Pereira, P. Valentão, J. M. A. Oliveira, J. Faria, L. Gaspar, M. Sottomayor, and P. B. Andrade, J. Pharm. Biomed. Anal., 2010, 51, 65.

25. S. S. Moon, A. A. Rahman, J. Y. Kim, and S. H. Kee, Bioorg. Med. Chem., 2008, 16, 7264. 